\title{
Preparation of Carbon Fiber Fabrics from Phenolic Resin by Electrospray Deposition
}

\author{
Kenichi Suzuki, ${ }^{1}$ Hidetoshi Matsumoto,${ }^{1}$ Mie Minagawa, ${ }^{1}$ \\ Masaru KIMURA, ${ }^{2}$ and Akihiko TANIOKA ${ }^{1, \dagger}$ \\ ${ }^{1}$ Department of Organic and Polymeric Materials, and International Research Center of Macromolecular Science, \\ Tokyo Institute of Technology, Mail Box S8-27, 2-12-1 Ookayama, Meguro-ku, Tokyo 152-8552, Japan \\ ${ }^{2}$ Technical Department, Gun-ei Shoji Co., Ltd., 700 Shukuorui-machi, Takasaki 370-0032, Japan
}

(Received June 29, 2007; Accepted July 24, 2007; Published September 7, 2007)

\begin{abstract}
Flexible carbon fiber fabrics of $1.7 \mu \mathrm{m}$ diameter fiber were prepared by electrospray deposition (ESD) from phenolic resin/poly(vinyl butyral) and successive curing and carbonization. In the present study, phenolic resin (thermostable 3-dimensional cross-linked polymer) was used for ESD and successive carbonization. The bead-free fiber was obtained by ESD from a phenolic resin solution with concentration above $55 \mathrm{wt} \%$. The as-deposited fabrics, however, were very brittle. The addition of poly (vinyl butyral) $\left(M_{\mathrm{w}}=110,000\right)$ improved the dimensional stability of the as-deposited fabrics. After carbonization of the as-deposited fabrics, the flexible carbon fiber fabrics were obtained. The carbon fiber fabrics showed relatively high electrical conductivity and a large specific surface area (BET surface area $=495 \mathrm{~m}^{2} / \mathrm{g}$ ). This indicates that the flexible carbon fiber fabrics are applicable not only for adsorbent and composite materials but also for materials for electronic device use. [doi:10.1295/polymj.PJ2007091]

KEY WORDS Electrospray Deposition / Phenolic Resin / Carbonization / Carbon Fiber /
\end{abstract}

Recently, increasing attention to nanomaterials has been focused on the carbon-based ones such as carbon nanotube (CNT), carbon nanofiber, and fullerene due to their electrical, thermal, and mechanical properties. Particularly, carbon nanofiber has a high surface area, lightweight, high electrical conductivity (comparable to CNT), ${ }^{1}$ and is low-cost in the production process. ${ }^{2-4}$ In addition, it is pointed out that carbon fibers with thinner diameters have a higher specific surface area and a higher electrical conductivity. In the cases of both carbon nanofibers and assemblies of carbon nanofibers, a free-standing carbon fibrous fabric is required for the applications such as electrodes, super capacitors, catalyst supports, emitter, sensor substrates, filter media, and reinforcements. If this fabric is flexible, its application is expanded much more. Conventional carbon fibers are produced by melt spinning and chemical vapor deposition (CVD). The melt spinning produces carbon fibers with diameters of more than $5 \mu \mathrm{m}$. The CVD method, on the other hand, synthesizes carbon fibers with diameters ranging from $10 \mathrm{~nm}$ to several microns. ${ }^{5,6} \mathrm{CVD}$, however, is not suitable for producing long fibers and nonwoven fabrics.

Electrospray deposition (ESD) has been expected to prepare a free-standing carbon fibrous fabric. ESD is a straightforward and versatile method for forming thin films. ${ }^{7}$ One major advantages of ESD is easily forming nano-microscaled fibrous fibers (typically nonwo- ven fabrics) from organic and inorganic materials. ${ }^{8-11}$ The ESD methods consist of the following steps; (i) a strong electric field is applied between a nozzle containing the polymer solution and a conductive substrate, (ii) when the voltage reaches a critical value, electrostatic forces overcome the surface tension of the solution, (iii) charged droplets (or jets) are sprayed from the tip of the nozzle, in a dry atmosphere; and (iv) the dried droplets (or jets) are finally collected on the substrate to form a thin film. ${ }^{12-14}$ We can control the fiber diameter by changing the solution properties (e.g., viscosity) and operational conditions (e.g., the distance between the nozzle tip and the substrate surface, the flow rate, and applied voltage). ${ }^{15}$

Several studies showed the preparation of carbon nanofibers through carbonization of electrospun polyacrylonitrile (PAN) nanofibers. ${ }^{16-18}$ The electrospun PAN fibers, however, can not maintain their shapes during the heat treatment before carbonizing due to their low thermal stability. Therefore, we adopted a phenolic resin which is a thermostable polymer to form a three-dimensionally linked structure for ESD. It is expected that the electrospray-deposited fabrics from phenolic resin would maintain their shapes during the heating treatment. The purpose of this investigation is to prepare free-standing and flexible carbon fiber fabrics from phenolic resin by ESD and successive carbonization.

${ }^{\dagger}$ To whom correspondence should be addressed (Tel: +81-3-5734-2426, Fax: +81-3-5734-2876, E-mail: tanioka.a.aa@m.titech.ac.jp). 


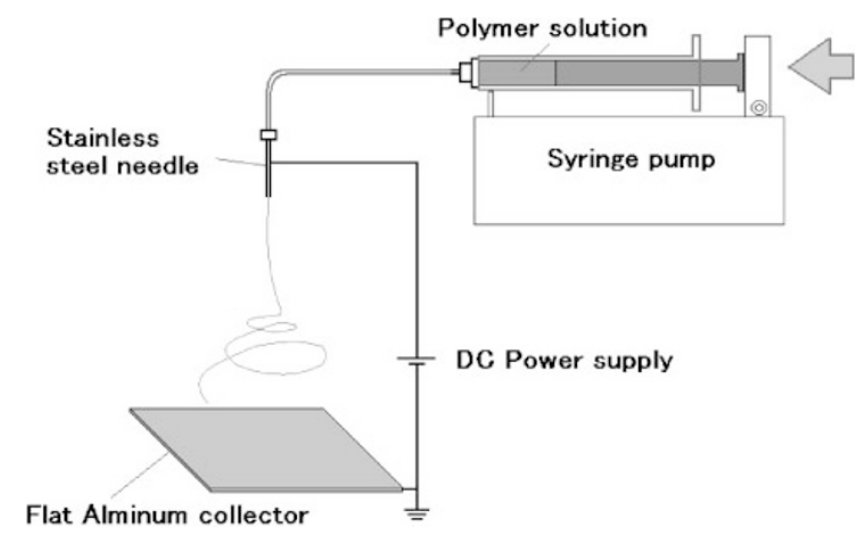

Figure 1. Schematic diagram of the apparatus used for electrospray deposition.

\section{EXPERIMENTAL}

\section{Materials}

Phenolic resin (novolac type, $M_{\mathrm{w}}=4,000-5,000$ ) was obtained from Gunei Chemical Industry Co., Ltd. Poly(vinyl butyral) (PVB, $\left.M_{\mathrm{w}}=110,000\right)$ and methanol were from Wako, Japan and used as the additive and solvent, respectively. These reagents were of extra-pure or pure grade and were used without further purification.

\section{Preparation of Polymer Solution}

Phenolic resin was dissolved in $\mathrm{MeOH}$ at various concentrations. PVB was added to some solutions. The viscosities of all solutions were measured with an oscillating-type viscosity meter (VM-100A, CBC Materials, Co., Ltd.) at $25^{\circ} \mathrm{C}$.

\section{Electrospray Deposition (ESD)}

A scheme of the ESD device is shown in Figure 1. The ESD device consists of a syringe-type infusion pump (MCIP-III, Minato Concept, Inc.), a high voltage regulated DC power supply (HDV-20K 7.5STD, Pulse Electronic Engineering, Japan), and a grounded collector (aluminum sheet, $10 \times 10 \mathrm{~cm}^{2}$ area). The polymer solutions were contained in a syringe with a stainless steel nozzle $(1.0 \mathrm{~mm}$ internal diameter). The applied voltage was $15 \mathrm{kV}$, the distance from the tip of the needle to collector was $10-20 \mathrm{~cm}$, and the flow rate of solution was 0.01 to $0.20 \mathrm{~mL} / \mathrm{min}$. Deposition was carried out at about $25^{\circ} \mathrm{C}$ and at less than a $35 \%$ relative humidity.

\section{Curing and Carbonization}

The as-deposited fabrics were cured by adding formaldehyde and then carbonized at $900^{\circ} \mathrm{C}$ in a ceramic furnace for $2 \mathrm{~h}$ under a continuous nitrogen purge. The carbonization yield was around $55 \%$.

\section{Characterization of Fabrics}

The surface morphologies of the phenolic resin fabrics before and after carbonization were observed using a scanning electron microscope (SEM, SM-200, Topcon, Japan) operated at $10 \mathrm{kV}$. All the SEM samples were sputter-coated with Au. Adsorption isotherms and the Brunauer-Emmett-Teller (BET) specific surface area ${ }^{19}$ of the carbonized fabric (phenolic resin/PVB: $97 / 3 \mathrm{w} / \mathrm{w}$ ) were determined using an adsorption apparatus (ASAP 2010, Micromeritics, USA). Carbon dioxide was selected as the probe molecule. To specify the pore size within the range of the size of $3 \mathrm{~nm}-500 \mu \mathrm{m}$ on the carbon fiber, mercury porosimetry measurement was carried out by an instrument (Auto Pore 9520, Micromeritics, USA). The electrical conductivities along the surface direction of the fabric $(20 \times 20 \times 0.17 \mathrm{~mm})$ were measured by a transmission-line modeling method using an analyzer (HP4142B, Agilent, USA). The sputtered Au $(3 \times 3 \mathrm{~mm})$ were used for the electrode and the distance between a pair of the electrodes was $2 \mathrm{~mm}$.

\section{RESULTS AND DISCUSSION}

\section{Preparation of Phenolic Resin Fibers}

The effects of polymer concentration, flow rate, and the distance between the tip of the needle and the collector were examined regarding the morphology of fiber in order to control the morphology and diameter of the phenolic resin fibers by ESD.

At first, the fibers were prepared by ESD from the phenolic resin/ $\mathrm{MeOH}$ solutions of $20-80 \mathrm{wt} \%$ concentrations. Figures 2 and 3 show the surface SEM images of the as-deposited phenolic resin fabrics from the solutions of various concentrations, and the effect of polymer concentration on solution viscosity and morphology of phenolic resin fabrics. The phenolic resin solutions with a concentration of less than 60 wt \% showed a good ESD processability. On the contrary, we cannot spray the solutions with a concentration of above $65 \mathrm{wt} \%$, because the solutions were too viscous. The shape of the deposits changed from bead to bead-free fiber, via beaded fiber, with an increase in the polymer concentration. A bead-free fiber was formed above $55 \mathrm{wt} \%$ polymer concentration. The higher solution concentration tends to form a thicker fibrous structure: the mean fiber diameter was 2.3$11.5 \mu \mathrm{m}$. This trend corresponds to the effect of solution viscosity shown in our previous study using a high-molecular-weight linear polymer. ${ }^{15,20}$ The critical lower concentration for formation bead-free fiber of phenolic resin, $55 \mathrm{wt} \%$, is much higher than that for a high-molecular-weight linear polymer $\left(M_{\mathrm{w}}: 500,000\right), 5 \mathrm{wt} \% .{ }^{15}$ This is because that the molecular weight of the phenolic resin is low 

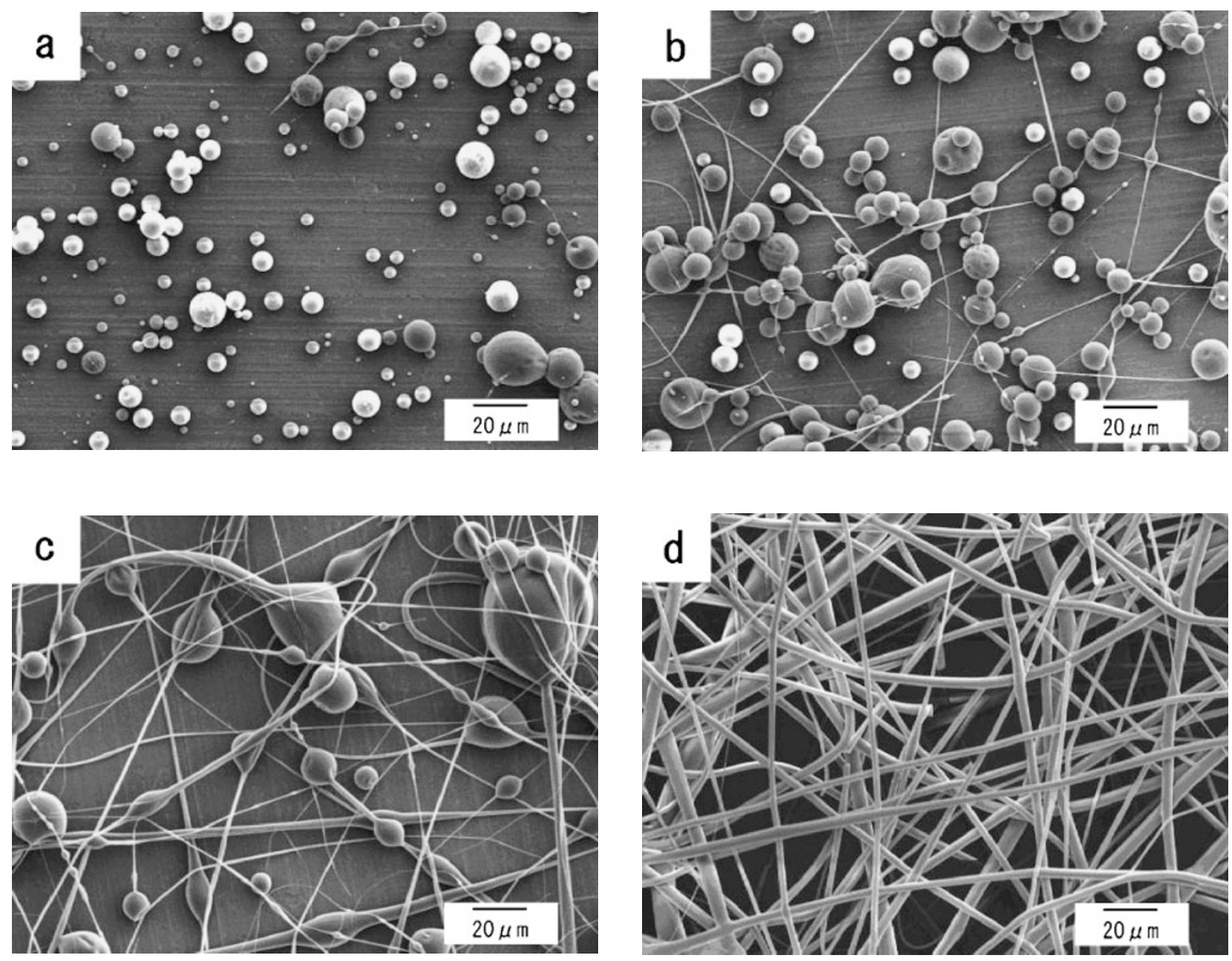

Figure 2. Continued on next page.

$(4,000-5,000)$, and the structure is extended threedimensionally.

Next, we examined the effect of operational conditions of the ESD process (i.e., flow rate, and the distance between the tip of the needle and the collector) on the diameter and the distribution of fiber diameter in the as-deposited fabrics in order to precisely control the morphology of the fabrics. The fabrics were prepared by ESD from a $55 \mathrm{wt} \%$ phenolic resin/ $\mathrm{MeOH}$ solution. The mean diameters and distribution of the fiber diameter in phenolic resin fabrics are summarized in Table I. Table I demonstrated that a lower flow rate tends to form a thinner fiber. The smaller value of standard deviation in Table I means a much sharper fiber distribution. The most uniform fibers were obtained at a $15 \mathrm{~cm}$ distance for each flow rate. The flow rate of $0.01 \mathrm{~mL} / \mathrm{min}$ gave the smallest value of mean diameter and standard deviation. However, the spraying mode at the tip of the noeedle during ESD was unstable. Therefore, we determined the ESD condition for stable production of the phenolic-resin fabrics with comparably thin diameter and narrow fiber diameter distribution: a polymer concentration of $55 \mathrm{wt} \%$, a flow rate of $0.05 \mathrm{~mL} / \mathrm{min}$, and the distance between the tip of the needle and the collector of $15 \mathrm{~cm}$.

The as-deposited fabrics were brittle and easily broken (Figure 4a) due to the existence of cracks on the fiber (Figure 4b). The generation of cracks would be attributed to the low of molecular weight and the three-dimensional structure of the phenolic resin.

\section{Addition Effect of PVB}

To improve the dimensional stability of the as-deposited phenolic resin fabrics (i.e., to prepare crackfree fibers), the addition effect of the high-molecular-weight linear polymers to the phenolic resin was investigated. Here we used PVB as the additive, because PVB shows a good compatibility with the phenolic resin/MeOH solution. We sprayed phenolic resin/ $\mathrm{MeOH}$ solution containing PVB (PVB content: 0.1 to $10 \mathrm{w} / \mathrm{w} \%)$. The spray mode was unstable by using the solution containing over $5 \mathrm{wt} \%$ PVB. The addition of a small amount of PVB improved the dimensional stability of the as-deposited fabrics (Figure 5a) due to the crack-free fiber in the fabric (Figure 5b). Particularly, the 99:1 and 97:3 w/w blends of phenolic resin 

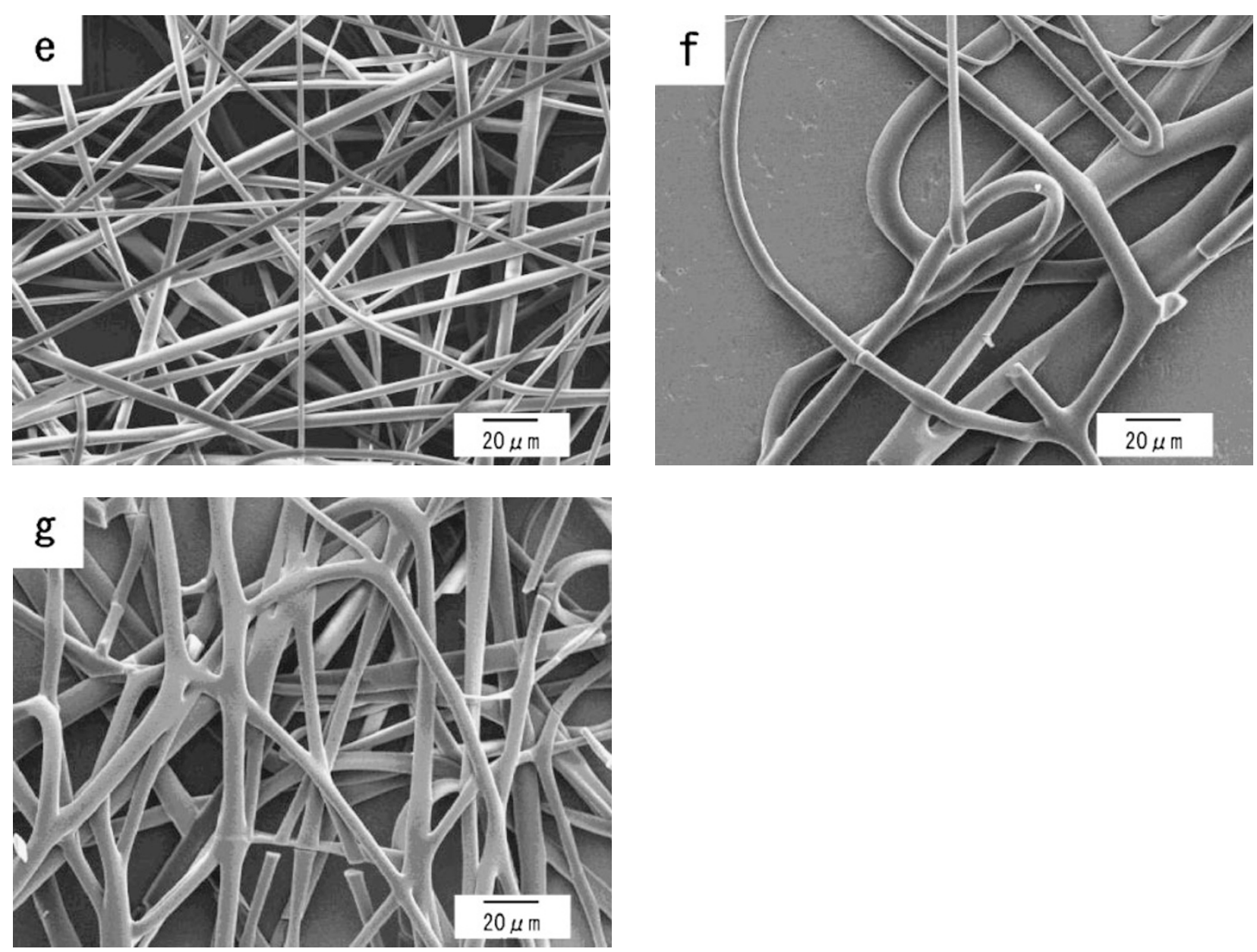

Figure 2. Surface SEM images of as-deposited phenolic resin fabrics from the solutions of various concentrations: (a) $40 \mathrm{wt} \%$, (b) $45 \mathrm{wt} \%$, (c) $50 \mathrm{wt} \%$, (d) $55 \mathrm{wt} \%$, (e) $60 \mathrm{wt} \%$, (f) $65 \mathrm{wt} \%$, and (g) $70 \mathrm{wt} \%$.

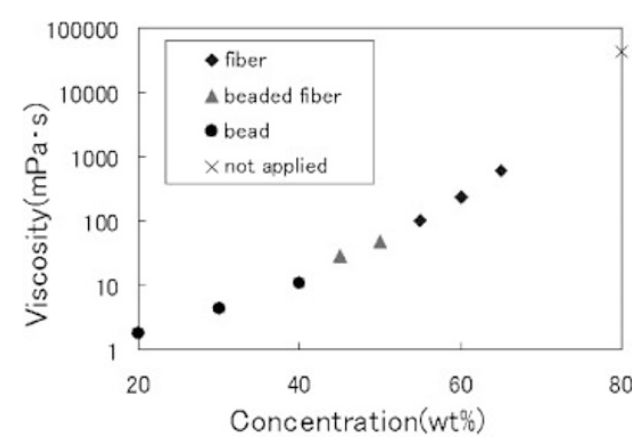

Figure 3. Effect of polymer concentration on solution viscosity and morphology of phenolic resin fabrics.

and PVB were effective (the blended solute: $\mathrm{MeOH}$ was $45: 55$ or $40: 60 \mathrm{w} / \mathrm{w}$ ). The addition effect of PVB on the formation of crack-free fiber would be due to the binder effect of high-molecular-weight linear polymer on formation of fibrous structure during ESD. ${ }^{21}$

When the fabric was grown from the solution (the blended solute: $\mathrm{MeOH}$ was 40:60 w/w), the mean diameter was $1.47 \mu \mathrm{m}$ for the $99: 1 \mathrm{w} / \mathrm{w}$ phenolic resin/ PVB blend and $2.86 \mu \mathrm{m}$ for the 97:3 blend. The fabric
Table I. Mean fiber diameters of phenolic resin fabrics prepared by ESD under various operational conditions

\begin{tabular}{cccc}
\hline $\begin{array}{c}\text { Amount of } \\
\text { sprayed } \\
\text { solution } \\
(\mathrm{mL} / \mathrm{min})\end{array}$ & $\begin{array}{c}\text { Distance } \\
\text { between } \\
\text { tip and } \\
\text { collector }(\mathrm{cm})\end{array}$ & $\begin{array}{c}\text { Mean } \\
\text { diameter } \\
(\mu \mathrm{m})\end{array}$ & $\begin{array}{c}\text { Standard } \\
\text { Deviation } \\
(\mu \mathrm{m})\end{array}$ \\
\hline 0.01 & 10 & 3.13 & 0.94 \\
0.01 & 15 & 2.63 & 0.74 \\
0.01 & 20 & 2.34 & 0.85 \\
0.05 & 10 & 3.57 & 1.00 \\
0.05 & 15 & 3.71 & 0.76 \\
0.05 & 20 & 3.20 & 1.00 \\
0.1 & 10 & 3.22 & 1.71 \\
0.1 & 15 & 3.51 & 1.34 \\
0.1 & 20 & 3.38 & 1.74 \\
0.2 & 10 & 4.69 & 2.66 \\
0.2 & 15 & 3.74 & 2.34 \\
0.2 & 20 & 4.17 & 2.92 \\
\hline
\end{tabular}

from the 97:3w/w blend showed better dimensional stability than that from the $99: 1 \mathrm{w} / \mathrm{w}$ blend. Therefore, we selected the $97: 3 \mathrm{w} / \mathrm{w}$ blend for the next curing and carbonization steps. 

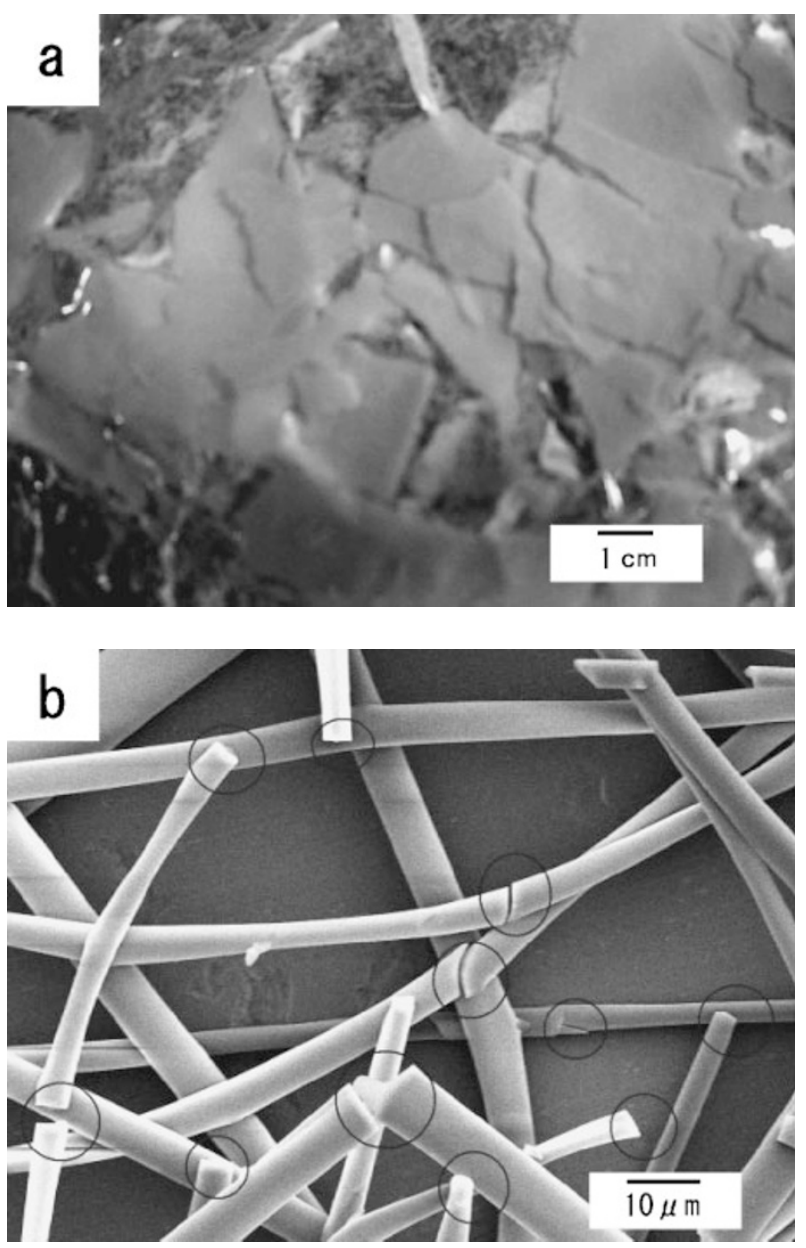

Figure 4. (a) Photograph (top view) and (b) SEM image of the as-deposited phenolic resin fabric from $55 \mathrm{wt} \%$ solution.

As can be seen in Figure 6, the morphologies of the fabrics from both the phenolic resin and the blend of phenolic resin and PVB depend on the solution viscosity as previously mentioned. The value of solution viscosity of $50 \mathrm{mPa}$ is the threshold between the fabrics with beaded fibers and those with bead-free fibers. The lower viscosity of the solution tends to form a thinner fibrous structure. Therefore, the increasing in the solution viscosity up to the $50 \mathrm{mPa}$ s is a reasonable approach for preparing bead-free and thin fibers by ESD.

\section{Carbonization}

The as-deposited phenolic resin fabrics were cured by adding formaldehyde with the acid catalyst to improve the dimensional stability before carbonization. Figure 7 shows that the fabrics maintained their dimension after carbonization. This would be due to the thermostability of the phenolic resin (The carbonized fiber prepared from electrospun PAN fiber is broken.). The carbonization yield was around 55\%. A free-standing (size: $10 \times 10 \mathrm{~cm}^{2}$; thickness: $0.12 \mathrm{~mm}$ ), flexible (see Figure 7e), and lightweight (density:
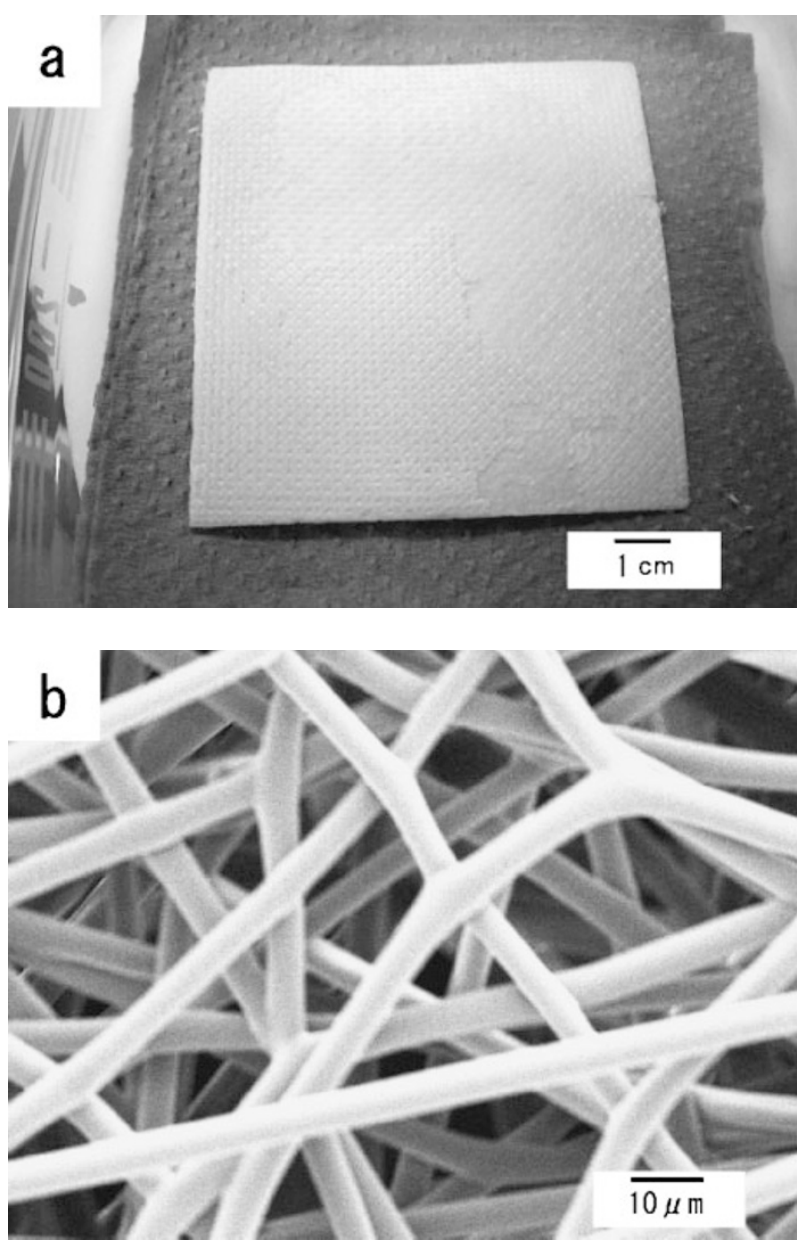

Figure 5. (a) Photograph (top view), and (b) SEM images of the as-deposited fabrics from 97:3 blends of phenolic resin and PVB (the solute $/ \mathrm{MeOH}=45 / 55 \mathrm{w} / \mathrm{w}$ ).

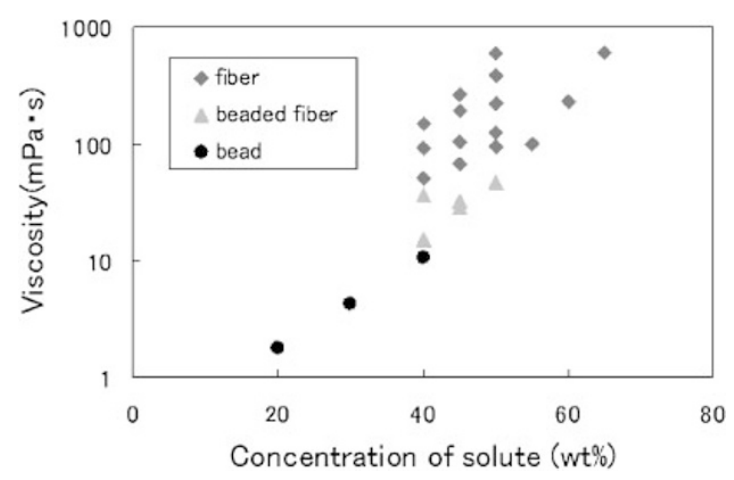

Figure 6. Effect of solute (phenolic resin and PVB) concentration on solution viscosity and morphology of phenolic resin fabrics.

around $0.15 \mathrm{~g} / \mathrm{cm}^{3}$ ) carbon fiber fabric was obtained. Figure 7 shows that the carbonization decreased the fiber diameter by around $1 \mu \mathrm{m}$ : the diameter is decreased from 4.36 to $3.57 \mu \mathrm{m}$ for the fabric from the solution (the blended solute: $\mathrm{MeOH}=45 / 55 \mathrm{w} / \mathrm{w}$ ) and from 2.68 to $1.72 \mu \mathrm{m}$ for the fabric from the solution (the blended solute: $\mathrm{MeOH}=40 / 60 \mathrm{w} / \mathrm{w}$ ). We 

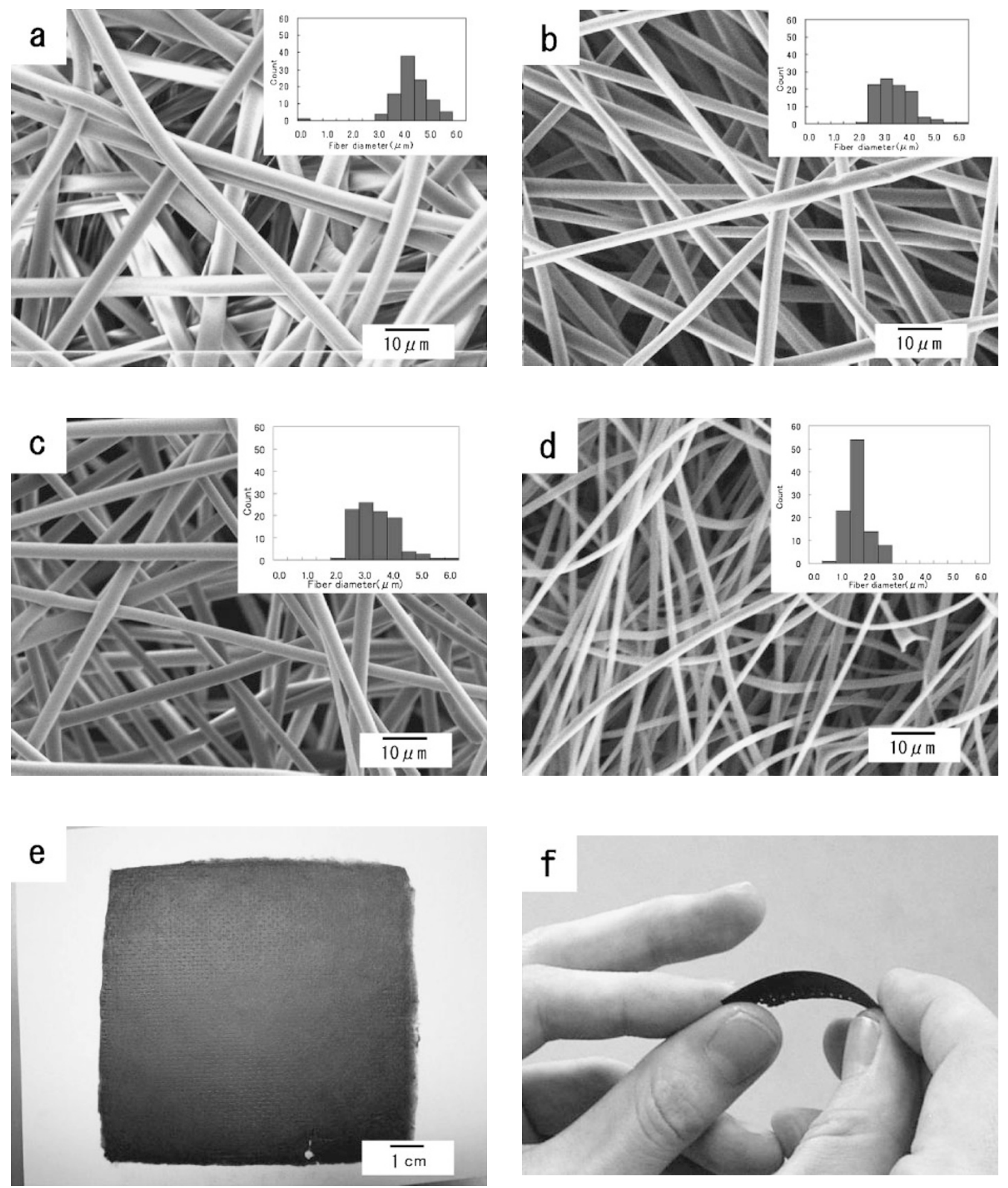

Figure 7. Surface SEM images of the as-deposited fabrics from (a) 97:3 blend of phenolic resin and PVB (the solute/MeOH $=45$ / $55 \mathrm{w} / \mathrm{w}$ ), (b) carbonized fabric of (a), (c) 97:3 blend of phenolic resin and PVB (the solute/MeOH $=40 / 60 \mathrm{w} / \mathrm{w}$ ), (d) carbonized fabric of $(c)$, and $(e, f)$ photographs of $(d)$. The insets in $(a-d)$ present the fiber diameter distribution estimated by image analysis.

could control the thickness of the carbon fiber fabric by changing the duration of the ESD process. We also believe that it is possible to prepare the carbon fiber fabrics with submicro-scaled diameter by controlling the solution composition for ESD and the temperature for carbonization as a further study.
The BET specific surface area of the carbon fabric was $495 \mathrm{~m}^{2} / \mathrm{g}$. This value is 5 times greater than the reported value for carbon fiber fabric with $1 \mu \mathrm{m}$ diameter fibers prepared by electrospinning from PAN. ${ }^{22}$ In addition, the BET surface area of the phenolic resinbased carbon fiber fabric is much higher than the val- 
ues for electrospun mats (i.e., $\left.2.1-51 \mathrm{~m}^{2} / \mathrm{g}\right)^{20}$ and equal to the values for activated carbon (phenolic resin is well-known as a material for activated carbon). ${ }^{23}$ The mercury porosimetry measurements showed that there is no significant peak in the range of the effective pore size $3 \mathrm{~nm}$ to $500 \mu \mathrm{m}$. This can be explained by the assumption that there are very small pores with the diameters of less than $3 \mathrm{~nm}$ on the surface of the carbon fibers. The phenolic resin-based carbon fiber fabric with a high specific surface area is a useful material for sorbent and filter media.

The electrical conductivities along the surface direction of the fabric $(10 \times 10 \times 0.17 \mathrm{~mm})$ were measured by a transmission-line modeling method. The carbon fabric showed an electrical resistance of $92.72 \Omega$, which compares with $19.20 \Omega$ for commercial carbon sheet $(10 \times 10 \times 0.20 \mathrm{~mm}$, TMIL Ltd., Japan). The difference might come from the contact interval and density. The fabric has also flexibility (Figure 7f) and is lightweight compared to metallic and inorganic materials. In addition, we can easily design diverse shapes of carbon fabrics by changing the shape of the collector for ESD. These advantages indicate that the flexible carbon fabric is a prospective organic material for electronic devices such as capacitors, electrodes, and substrates for emitters and solar cells.

\section{CONCLUSION}

In the present study, flexible carbon fabrics with $1.7 \mu \mathrm{m}$ diameter fibers were prepared by ESD from a phenolic resin/PVB blend solution and successive carbonization. The thermal stability of the phenolic resin is expected to maintain their shapes after carbonization. The as-deposited phenolic resin fabrics, however, were brittle. The addition of a small amount of high-molecular-weight polymer (PVB, $M_{\mathrm{w}}=$ $110,000)$ improved the dimensional stability of the as-deposited fabrics. The phenolic resin-based flexible carbon microfiber fabrics showed relatively high electrical conductivity and a large surface area (BET surface area $=495 \mathrm{~m}^{2} / \mathrm{g}$ ). The flexible carbon fiber fabrics open a new direction in the application of carbonbased materials (e.g., flexible electrodes and substrates for electronic devices). Further studies on electro-optical device based on the flexible carbon fiber fabrics are now in progress.
Acknowledgment. The authors thank Associate Professor Yasuhiko Hayashi (Nagoya Institute of Technology) for the conductivity measurements by the transmission-line modeling method.

\section{REFERENCES}

1. Y.-L. Li, I. A. Kinloch, and A. H. Windle, Science, 304, 276 (2004).

2. J. Doshi and D. H. Reneker, J. Electrostat., 35, 151 (1995).

3. D. H. Reneker and I. Chun, Nanotechnology, 7, 216 (1996).

4. C. Kim, K. Yang, and W. J. Lee, Electrochem. Solid-State Lett., 7, A397 (2004).

5. M. Endo, Y. A. Kim, T. Takeda, S. H. Hong, T. Matusita, T. Hayashi, and M. S. Dresselhaus, Carbon, 39, 2003 (2001).

6. G. B. Zheng, K. Kouda, H. Sano, Y. Uchiyama, Y. F. Shi, and H. J. Quan, Carbon, 42, 635 (2004).

7. G. M. H. Meesters, P. H. W. Vercoulen, J. C. M. Marijnissen, and B. Scarlett, J. Aerosol Sci., 23, 37 (1992).

8. V. N. Morozov and T. Y. Morozova, Anal. Chem., 71, 1415 (1999).

9. V. N. Morozov and T. Y. Morozova, Anal. Chem., 71, 3110 (1999).

10. V. N. Morozov, T. Y. Morozova, and N. R. Kallenbach, Int. J. Mass Spectrom., 178, 143 (1998).

11. P. Li and Y. Xia, Adv. Mater., 16, 1151 (2004).

12. D. H. Reneker and I. Chun, Nanotechnology, 7, 216 (1996).

13. J. Doshi and D. H. Reneker, J. Electrostat., 35, 151 (1995).

14. A. L. Yarin, S. Koombhongse, and D. H. Reneker, J. Appl. Phys., 90, 4836 (2001).

15. K. Morota, H. Matsumoto, T. Mizukoshi, Y. Konosu, M. Minagawa, and A. Tanioka, Y. Yamagata, and K. Inoue, J. Colloid Interface Sci., 279, 484 (2004).

16. I. Chun, D. H. Reneker, H. Fong, X. Fang, J. Dietzel, N. B. Tan, and K. Keams, J. Adv. Mater., 31, 36 (1999).

17. F. Ko, Y. Gogotsi, A. Ali, N. Naguib, H. Ye, G. Yang, C. Li, and P. Willis, Adv. Mater., 15, 1161 (2003).

18. Y. Wang, S. Serrano, and J. J. Santiago-Aviles, Synth. Met., 138, 423 (2003).

19. S. Brunauer, P. H. Emmett, and E. Teller, J. Am. Chem. Soc., 60, 309 (1938).

20. H. Matsumoto, Y. Wakamatsu, M. Minagawa, and A. Tanioka, J. Colloid Interface Sci., 293, 143 (2006).

21. H. Seo, H. Matsumoto, S. Hara, H. Yako, M. Minagawa, A. Tanioka, Y. Yamagata, and K. Inoue, Polym. J., 37, 391 (2005).

22. D. L. Gee, G. E. Wnek, S. M. Zhuang, J. M. Layman, and P. Lipowicz, Polym. Prepr., 44, 120 (2003).

23. E. Tanaka, H. Tatemoto, and I. Abe, in "Kasseitan no Ouyougijutsu," Techno System Co., Tokyo Japan, 1990, p65. 